\title{
Population-Related Variation in Plant Defense more Strongly Affects Survival of an Herbivore than Its Solitary Parasitoid Wasp
}

\author{
Jeffrey A. Harvey • Rieta Gols
}

Received: 15 March 2011 /Revised: 19 July 2011 /Accepted: 28 September 2011 / Published online: 11 October 2011

(C) The Author(s) 2011. This article is published with open access at Springerlink.com

\begin{abstract}
The performance of natural enemies, such as parasitoid wasps, is affected by differences in the quality of the host's diet, frequently mediated by species or population-related differences in plant allelochemistry. Here, we compared survival, development time, and body mass in a generalist herbivore, the cabbage moth, Mamestra brassicae, and its solitary endoparasitoid, Microplitis mediator, when reared on two cultivated (CYR and STH) and three wild (KIM, OH, and WIN) populations of cabbage, Brassica oleracea. Plants either were undamaged or induced by feeding of larvae of the cabbage butterfly, Pieris rapae. Development and biomass of M. brassicae and Mi. mediator were similar on both cultivated and one wild cabbage population (KIM), intermediate on the $\mathrm{OH}$ population, and significantly lower on the WIN population. Moreover, development was prolonged and biomass was reduced on herbivore-induced plants. However, only the survival of parasitized hosts (and not that of healthy larvae) was affected by induction. Analysis of glucosinolates in leaves of the cabbages revealed higher levels in the wild populations than cultivars, with the highest concentrations in WIN plants. Multivariate statistics revealed a negative correlation between insect performance and total levels of glucosinolates (GS) and levels of 3-butenyl GS. However,
\end{abstract}

\footnotetext{
J. A. Harvey $(\bowtie)$

Department of Terrestrial Ecology,

Netherlands Institute of Ecology,

Droevendaalsesteeg 10,

6708 PB Wageningen, The Netherlands

e-mail: j.harvey@nioo.knaw.nl

R. Gols

Laboratory of Entomology, Plant Sciences Group,

Wageningen University,

PO Box 8031, 6700 EH Wageningen, The Netherlands
}

GS chemistry could not explain the reduced performance on induced plants since only indole GS concentrations increased in response to herbivory, which did not affect insect performance based on multivariate statistics. This result suggests that, in addition to aliphatic GS, other nonGS chemicals are responsible for the decline in insect performance, and that these chemicals affect the parasitoid more strongly than the host. Remarkably, when developing on WIN plants, the survival of Mi. mediator to adult eclosion was much higher than in its host, M. brassicae. This may be due to the fact that hosts parasitized by $M i$. mediator pass through fewer instars, and host growth is arrested when they are only a fraction of the size of healthy caterpillars. Certain aspects of the biology and life-history of the host and parasitoid may determine their response to chemical challenges imposed by the food plant.

Key Words Glucosinolates · Parasitoid · Induction · Cabbage $\cdot$ Brassica oleracea $\cdot$ Microplitis mediator . Mamestra brassicae $\cdot$ Koinobiont

\section{Introduction}

Many studies have reported that the performance of insect natural enemies, such as parasitoid wasps, is affected by differences in the quality of the host's diet, frequently mediated by species or population-related differences in plant allelochemistry (Harvey, 2005; Ode, 2006; Gols and Harvey, 2009a). Thus far, most studies that have explored the effects of plant quality on the development of parasitoids have used koinobiont parasitoids of lepidopterous hosts. Koinobionts are parasitoids that attack hosts that continue feeding and growing throughout the course of parasitism (Askew and Shaw, 1986). In most of these 
studies, early stages (typically L1 or L2) of the host were attacked, whereby the hosts were a fraction of the size of the ovipositing female parasitoid. This means that the host had to grow considerably during the parasitism phase to achieve a size capable of supporting the minimal nutritional requirements of the parasitoid progeny. A commonly reported trend is that both hosts and parasitoids perform equally well (or poorly) on plants of a given quality, suggesting that the effects of plant-related traits on parasitoid performance are similar up the food chain (Barbosa et al., 1986; Gunasena et al., 1990; Ode et al., 2004; Harvey et al., 2005; Gols et al., 2008a,b; Morse, 2009; Lampert and Bowers 2010).

The effects of plant quality on the development of herbivores (and, by association their parasitoids), often has been invoked on the basis of extrinsic threats to survival. The 'slow-growth-high-mortality' hypothesis posits that the growth of hosts feeding on nutritionally poor diets will be prolonged, thus extending their 'window of susceptibility' to a suite of natural enemies such as predators and parasitoids as well as to abiotic stresses (Benrey and Dennor, 1997; Fordyce and Shapiro, 2003). Because the mortality of the parasitoid is proportional to that of the host during the interaction, parasitoids also will die in hosts that suffer precocious mortality as a result of pathogens of predators (Fritz, 1982). However, less attention has been paid to exploring the effects of plant quality on intrinsic (host-related) threats to the survival of parasitoids and to how these are temporally correlated. For instance, if the effects of ingested plant toxins are gradual and cumulative on the host, we might expect that parasitoids that terminate their relationship with the host earlier would survive better than parasitoids that emerge from older hosts. This would be especially true if host and parasitoid mortality are proportional on specific herbivore diets.

An important aspect of parasitoid biology that may be linked to differences in host plant quality is how the wasp regulates host growth relative to that of healthy hosts. This parameter is intimately correlated with the size of the adult parasitoid relative to the maximum potential size of its herbivore host. In many associations that involve macrolepidopteran hosts and their solitary koinobiont endoparasitoids, host growth is reduced by $90 \%$ or more, compared with healthy hosts (Jones and Lewis, 1971; Vinson, 1972; Smilowitz and Iwantsch, 1975; Harvey et al., 1999, 2004, 2010a). In other host-parasitoid associations, however, regulation of host growth is more subtle or absent entirely, at least in examples where the maximum size of healthy hosts and adult parasitoid size are not markedly different (Harvey et al., 1994; Gols and Harvey, 2009b). In situations where hosts pass through fewer instars and/or growth is arrested earlier in development, we might expect the development of solitary parasitoids to be less constrained by differences in plant quality than in situations where hosts must grow larger to satisfy the nutritional requirements of the parasitoid offspring. However, as far as we know, this assumption remains untested.

Here, we compared development of the cabbage moth, Mamestra brassicae L. (Lepidoptera: Noctuidae) and its solitary koinobiont endoparasitoid, Microplitis mediator Haliday (Hymenoptera: Braconidae) on wild cabbage plants originating from three populations growing naturally along the Dorset coast of Great Britain, as well as on two cultivars. Like other members of the large family Brassicaceae, cabbage plants produce inducible glucosinolates (hereafter GS) (Fahey et al., 2001). Glucosinolates and their breakdown products negatively affect the growth and/or development of herbivores (Li et al., 2000; Buskov et al., 2002; Agrawal and Kurashige, 2003; Hopkins et al., 2009). Previous work has shown that wild cabbages exhibit strong inter- and intrapopulation variation in heritable aliphatic GS (Giamoustaris and Mithen, 1995; Moyes et al., 2000; Gols et al., 2008a; Newton et al., 2009a,b). Cultivated cabbage is an important global crop. Due to the effects of artificial selection via domestication, plant breeders have often sought to reduce levels of foliar GS and to eliminate variation in various other plant traits (Gols and Harvey, 2009a). Despite this, cultivated strains of cabbage have been used extensively in ecological and behavioral studies (reviewed by Hopkins et al., 2009).

Here, survival, body mass and larval development time of M. brassicae and Mi. mediator were examined on three wild strains and two cultivars of $B$. oleracea that were either undamaged or induced by herbivore feeding. The three main aims of the current study were: (1) to compare the performance of an herbivore and its parasitoid on the various cabbage strains and to see if effects of plant quality on insect performance are similar in both organisms; (2) to determine if the effects of plant quality on development of male and female parasitoids are similar; and (3) to measure differences in GS concentrations in the three wild populations and two cultivars of $B$. oleracea, and by using these data, to determine if insect performance is correlated with qualitative or quantitative aspects of plant allelochemistry. We hypothesized: (1) that there would be a strong link between plant quality and both herbivore and parasitoid performance; (2) that this parameter would be correlated with total amounts of GS present in leaf tissues of $B$. oleracea; and (3) that previous herbivore damage would lead to increased levels of plant defense and that this also would be reflected in insect performance.

\section{Methods and Materials}

Plants Seeds of wild B. oleracea plants were collected from three populations growing in meadows adjacent to chalk cliffs along the south coast of Great Britain to the 
west and north of Swanage, Dorset. The populations are located at sites known as 'Old Harry' $\left(50^{\circ} 38^{\prime} \mathrm{N}, 1^{\circ} 55^{\prime} \mathrm{E}\right)$, 'Winspit' $\left(50^{\circ} 35^{\prime} \mathrm{N}, 2^{\circ} 02^{\prime} \mathrm{E}\right)$, and 'Kimmeridge' $\left(50^{\circ} 36^{\prime} \mathrm{N}\right.$, $\left.2^{\circ} 07^{\prime} \mathrm{E}\right)$. In addition, two cultivated strains of $B$. oleracea: Brussels sprouts (var. gemmifera) cv. 'Cyrus', on which the lab culture of $M$. brassicae had been reared for many generations, and white cabbage (var. alba) cv. "Stonehead" were used. For simplicity, we also refer to the cultivars as 'populations'. Hereafter, the populations are abbreviated as $\mathrm{OH}$ (Old Harry), WIN (Winspit), KIM (Kimmeredge), CYR (Cyrus cultivar), and STH (Stonehead cultivar).

Seeds from the various populations were germinated in moist soil, and the seedlings were transferred to 2.1-1 pots that had been filled with potting soil ('Lentse potgrond' no. 4, Lent, The Netherlands). Plants were grown in facilities operated by Unifarm at Wageningen University (WU), The Netherlands, in a greenhouse compartment at $18-25^{\circ} \mathrm{C}$, $50-70 \%$ r.h. with a photoperiod of at least $16 \mathrm{hr}$. If the light intensity dropped below a level of $500 \mu \mathrm{mol}$ photons $\mathrm{m}^{2} / \mathrm{s}$ during the $16 \mathrm{hr}$ photoperiod, supplementary illumination was supplied by high pressure mercury lamps. All plants were uniformly watered on a daily basis. When plants were 4 wk-old, they were fertilized once a week with Kristallon Blauw (16 N:6 P:20 K:3 Mg) at a concentration of $2.5 \mathrm{mg} / \mathrm{l}$. Plants were 7 wk-old at the start of the experiments. Watering and fertilization continued during the experiments.

Insects Larvae of $M$. brassicae were collected originally from cabbage fields grown in the vicinity of Wageningen University, and had been reared for many years in the laboratory on Brussels sprout (B. oleracea var. gemmifera cv. Cyrus) plants. Mamestra brassicae is native to the Palearctic, considered to be a generalist herbivore, and is frequently a pest in cabbages and other crops. Newly emerged moths were placed in groups of 20 into plastic containers (35 by $20 \mathrm{~cm}$ ) with $10 \%$ sugar solution absorbed into cotton wool in small plastic vials. Filter paper was placed into the containers as a cover, and the moths laid their eggs onto this substrate. Every day the filter paper was removed and stored at $7^{\circ} \mathrm{C}$ pending hatching. New filter paper was placed inside and over the containers. Microplitis mediator was collected from young M. brassicae caterpillars on potted cabbage plants that had been placed for a week into a flowering meadow adjacent to the Laboratory of Entomology at Wageningen University. This parasitoid also is native to Eurasia and develops in first (L1) to third (L3) instars of its hosts. It is a specialist of species of moths in the family Noctuidae. In Europe, M. brassicae is considered to be its most important host. Like other members of the higher Microgastrinae, larvae of $M i$. mediator feed exclusively on host hemolymph, and thus consume only a small proportion of available host tissues. At maturity, the parasitoid larva perforates a hole in the side of the host and emerges to spin a brown, papery cocoon. The host dies within a few days.

Several hundred newly hatched L1 caterpillars were placed onto cabbage plants in a rearing cage $(40 \times 40 \times$ $60 \mathrm{~cm}$ ) and allowed to feed. After $24 \mathrm{hr}, 60$ wasps $>5 \mathrm{~d}$-old (about half of each sex) were released into the cage and allowed to parasitize the larvae for several days. Sugar solution was provided constantly, and new plants were supplied as necessary for the larval development. Larvae were allowed to develop until parasitoid egression and pupation. Cocoons of $\mathrm{Mi}$. mediator were collected from cages and placed into large Petri dishes (15 cm dia.) until parasitoid eclosion.

Insects were reared in climate rooms at $23 \pm 2^{\circ} \mathrm{C}$ with a 16:8 hr L:D photoperiod.

Development of Mamestra brassicae and Microplitis mediator on Induced and Non-induced Brassica oleracea Leaves Healthy hosts: Egg batches of M. brassicae were allowed to hatch on the filter paper. Neonate larvae then were randomly allocated to $9.5-\mathrm{cm}$ Petri dishes (7 larvae per dish) with excised middle-aged leaves from each of the 10 following plant treatments: induced or non-induced plants from the cultivars (CYR, STH) or from the wild populations $(\mathrm{OH}, \mathrm{KIM}, \mathrm{WIN})$, with 10 dishes used per treatment. To induce $B$. oleracea plants, 10 L1 Pieris rapae larvae (distributed over 3 leaves) were allowed to move freely around and feed on the plants for $7 \mathrm{~d}$ after which time they were removed. Sections of leaf tissue from the herbivore-damaged or undamaged plants were provided as food for the caterpillars in the Petri dishes. Induced plants were prepared every $2 \mathrm{~d}$.

A disc of moistened filter paper was inside each dish to prevent leaf tissues from desiccating. Every $2 \mathrm{~d}$, leaf materials as well as the filter papers were replaced, and mortality of the larvae was recorded. Healthy larvae grow much larger than parasitized larvae. Therefore, healthy larvae from each Petri dish were transferred to larger plastic containers $(15 \times 10 \times 10 \mathrm{~cm})$ when they were L4. Mature larvae normally burrow into the soil in order to pupate; here, mature L5 larvae were provided with a layer of vermiculite approximately $3 \mathrm{~cm}$ deep in plastic boxes for this purpose. Pre-pupae that had stopped feeding and were in the vermiculite were carefully checked every day in order to determine when they had pupated. Fresh pupae were removed and weighed on an analytic balance (accuracy $\pm 0.1 \mathrm{mg}$ ). Larval development time was determined as the number of days between hatching and pupation.

Parasitized hosts: Newly molted L2 caterpillars that had been feeding on either non-induced or induced excised leaf tissues from the various cabbage populations were presented individually to mated female $\mathrm{Mi}$. mediator wasps on 
the end of a brush in small plastic vials. Parasitism was verified by a single insertion and removal of the ovipositor. Parasitized caterpillars then were placed into 9.5-cm Petri dishes (7 caterpillars per dish, 12 dishes per treatment) lined with moistened filter paper and provided with excised leaves from the same treatment group as they had been feeding on previously. Every $2 \mathrm{~d}$, leaf materials as well as filter papers were replaced, and mortality of the larvae was recorded. Parasitoid larvae typically egress from the host and pupate after 8-9 d. Cocoons were transferred to and maintained individually in labeled glass vials. Newly emerged adult wasps were sexed, narcotized using $\mathrm{CO}_{2}$, and weighed on a microbalance (accuracy $1 \mu \mathrm{g}$ ). Parasitoid eclosion was checked several times over the course of $24 \mathrm{hr}$. Development time (in hours) was determined as the duration between parasitism and adult emergence. All experiments were conducted in climate rooms at $23 \pm 2^{\circ} \mathrm{C}$ with a $16: 8 \mathrm{hr} \mathrm{L}: \mathrm{D}$ photoperiod.

Glucosinolate Analysis GS concentrations were measured in leaf tissues sampled from 8 to 10 plants from each treatment $\times$ population combination. Plants induced by $P$. rapae feeding were prepared similarly as in the developmental experiments. Non-induced and herbivore-induced plants were of the same age, and all plants were sampled at the same day. Two discs, 17-mm diam, were punched per leaf, one from each central part of a leaf half, and 6 fully unfolded leaves were sampled per plant. Leaf discs were pooled per plant and frozen in liquid nitrogen immediately after sampling and then stored at $-80^{\circ} \mathrm{C}$. Samples were later freeze-dried and pulverized. Glucosinolates were extracted using a methanol extraction, identified and quantified as described by van Dam et al. (2004). Briefly, GS were extracted with boiling $70 \%$ methanol solution, desulphatased with arylsulphatase on a DEAE-Sephadex A 25 column, and separated on a reversed phase C-18 column on HPLC with an acetonitril-water gradient. Detection was performed with a single wavelength detector set to $226 \mathrm{~nm}$, with sinigrin used as an external standard.

Glucosinolates were classified based on their amino-acid origin into indole GS (derived from tryptophan), aromatic GS (derived from phenylanaline), and alipathic GS (derived from methionine). The latter group was further divided according to GS modification steps into sulfinyl, alkenyl, and hydroxylated GS (Halkier and Gershenzon, 2006).

Statistics To compare the effect of plant population and induction on the fitness correlates, development time, and body mass of both the herbivore and the parasitoid, we used an analysis of variance model with fixed (population and induction) and one random variable (Petri dish $=$ replicate). In the analysis of the Mi. mediatior data, we also included sex as a fixed factor. The estimation of the effects in the model was based on restricted likelihood maximization
(REML). The Satterthwaite method was used for approximating the denominator degrees of freedom for the $F$-tests of the fixed effects (Littell et al., 2002). To compare GS concentrations, we used a general linear model ANOVA with population and induction as factors. Development times were $\log$ transformed, and GS concentrations were $\log (\mathrm{x}+1)$ transformed to meet assumptions of normality and equal variances. Data on the survival were analyzed by using non-parametric Kaplan-Meier survival analyses. The log-rank test was used to compare survival curves. Data were analyzed separately for the herbivore and the parasitoid. Parasitized hosts that did not produce a parasitoid were excluded from the analyses. All analyses were carried out using the statistical package SAS 9.1.

Multivariate statistics (PLS $=$ Projection to Latent Structures) was used to reveal whether the variation in GS chemistry could explain the variation in the performance of the herbivore and the parasitoid. We used the PLS extension of the SIMCA P+ 12.0 software program (Umetrics AB, Umeå, Sweden) The program's cross validation procedure evaluates the significance of each additional component (starting with none) by comparing the goodness of fit $\left(\mathrm{R}^{2}\right)$ and the predictive value $\left(\mathrm{Q}^{2}\right)$ of the extended model with that of the reduced model. First, we ran the PLS analysis with all variables, and then we eliminated those GS variables from the model that contributed little to explaining the variation based on the variable importance on projection values (VIP values). Variables with VIP values $>1$ are most influential to the model (Eriksson et al., 2006). Per leaf sample, concentrations of the individual GS compounds, pooled levels for each of the GS classes as described in GS analysis section, served as variables in the model. Data were log transformed, mean-centered, and scaled to unit variance before they were subjected to analysis. Insect performance data, which represented the Y-matrix variables, included for the herbivore development time, pupal mass, and survival; and for the parasitoid for both sexes separately, development time, adult body size, and survival to cocoon formation (male and females combined).

\section{Results}

Development of Mamestra brassicae and Microplitis mediator on Induced and Non-induced Brassica oleracea Leaves Both development time $\left(F_{4,73.7}=270, P<0.001\right)$ and pupal mass $\left(F_{4}, 92.3=100, P<0.001\right)$ of the herbivore $M$. brassicae were affected by the plant population on which the caterpillars had been feeding previously (Fig. 1a and b). Development time $\left(F_{1,64.4}=158, P<0.001\right)$ was longer and pupal mass $\left(F_{1,75.3}=52.1, P<0.001\right)$ was lower 

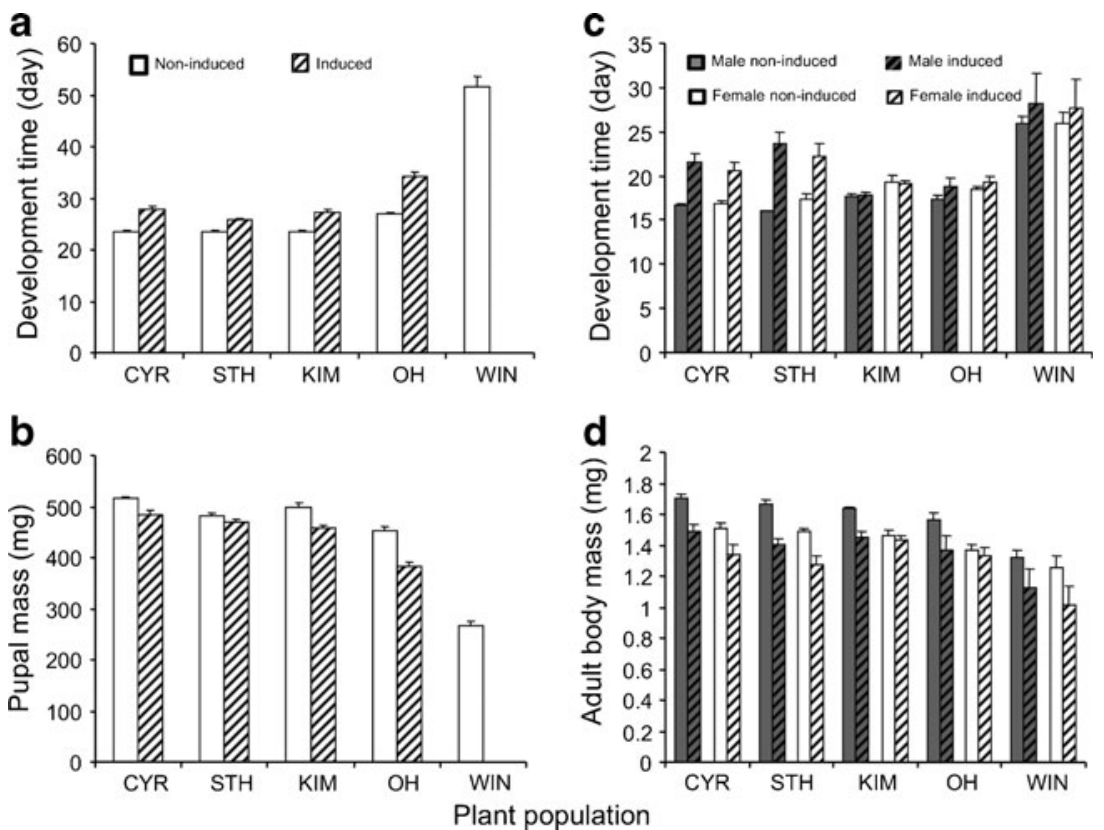

Fig. 1 Fitness correlates (development time and mass) of the herbivore Mamestra brassicae (a, b) and its parasitoid Microplitis mediator $(\mathbf{c}, \mathbf{d})$ when they were reared on cultivated (CYR or STH) or wild (KIM, OH, WIN) cabbage (Brassica oleracea). Hosts (healthy or parasitized) were reared in Petri dishes and provided with leaf tissues collected from non-

on induced compared to non-induced plants (Fig. 1a and b). Induction differentially affected development time and pupal mass depending on the population on which the caterpillars had previously been feeding (population-induction interaction for development time $F_{3,64.4}=5.68, P=0.002$, and for pupal mass $F_{3,75.3}=5.12, P=0.003$ ). The effect of induction was strongest for WIN plants, as none of the larvae developed into pupae when they had been feeding on induced WIN plant tissues. Larval survival to pupation was high; more than $90 \%$ of the larvae successfully developed into pupae on all plant populations with the exception of the WIN population (Fig. 2a). Survival curves of larvae feeding on induced and non-induced leaf tissues were significantly different for the WIN population only (log-rank test, $P<0.001$ ).

Development time and biomass of the parasitoid on the various populations, exposed to previous feeding or not, reflected that of healthy hosts (Fig. 1). Plant population had an effect on development time of the wasps $\left(F_{4,99.7}=39.4\right.$, $P<0.001)$; development time was longest on WIN leaf tissues. Moreover, the development time of the wasps was longer on induced than on non-induced plants $\left(F_{1,110}=40.4\right.$, $P<0.001)$, and induction affected development differently depending on the plant population (population-induction interaction, $\left.F_{4,109}=8.80, P<0.001\right)$. Previous herbivory tended to prolong development more on cultivated than on wild cabbage. The plant-sex interaction term also was significant $\left(F_{4}, 331=3.96, P=0.004\right)$; females tended to develop slower than males on $\mathrm{OH}$ and KIM plants, while induced plants (open bars) or from plants that had been exposed to Pieris rapae feeding for $7 \mathrm{~d}$ (hatched bars). Leaf tissues were replaced every other day. Parasitoids data are given for males (grey or hatched grey bars) and females (white or hatched white bars) separately. Bars are the mean values $(+\mathrm{SE})$ based on pooled data per dish

on the other populations this pattern was less clear. Plant population $\left(F_{4,114}=19.9, P<0.001\right)$, induction $\left(F_{1,130}=38.9\right.$, $P<0.001)$ and sex $\left(F_{1,478}=33.9, P<0.001\right)$, all affected biomass of the adult wasps, with wasps being smaller on induced than on non-induced plants, and males being larger than females. Induction affected adult biomass of the males more strongly than that of the females (induction-sex interaction $\left.F_{1}, 478=4.49, P=0.03\right)$. Compared to healthy hosts, survival to pupation was more idiosyncratic for the parasitoid (Fig. 2b). Survival was higher on non-induced than on induced plant tissues for all populations except for the KIM populations (log rank tests: WIN, $P<0.001$; STH, $P<0.001$, OH, $P=0.003$, CYR, $P=0.02$, KIM, $P=$ $0.95)$. When survival curves on non-induced plant tissues were compared, it was similar on KIM, OH, and STH (log rank test was no longer significant after successive omission of CYR and WIN data). Using a similar approach, survival on induced plant tissues was not significantly different for $\mathrm{OH}$, KIM and CYR plants.

Glucosinolate Analysis GS profiles differed profoundly for the different plant populations (Fig. 3). In CYR plants, the profile was dominated by sulfinyl GS (primarily 3methylsulfinylpropyl GS), whereas in STH plants, it was dominated by alkenyl GS (primarily 2-propenyl GS). In the wild populations, there was both quantitative and qualitative variation in GS profiles. WIN plants produced high levels of alkenyl GS (especially 3-butenyl GS), and most 
Fig. 2 Survival curves of healthy unparasitized Mamestra brassicae caterpillars (a) and caterpillars parasitized by Microplitis mediator (b). Survival was measured from hatching to pupation for healthy $M$. brassicae and for Mi. mediator from oviposition until cocoon formation. A few parasitized caterpillars developed into healthy caterpillars. These caterpillars were either not parasitized or the eggs were encapsulated and these were excluded from the data set

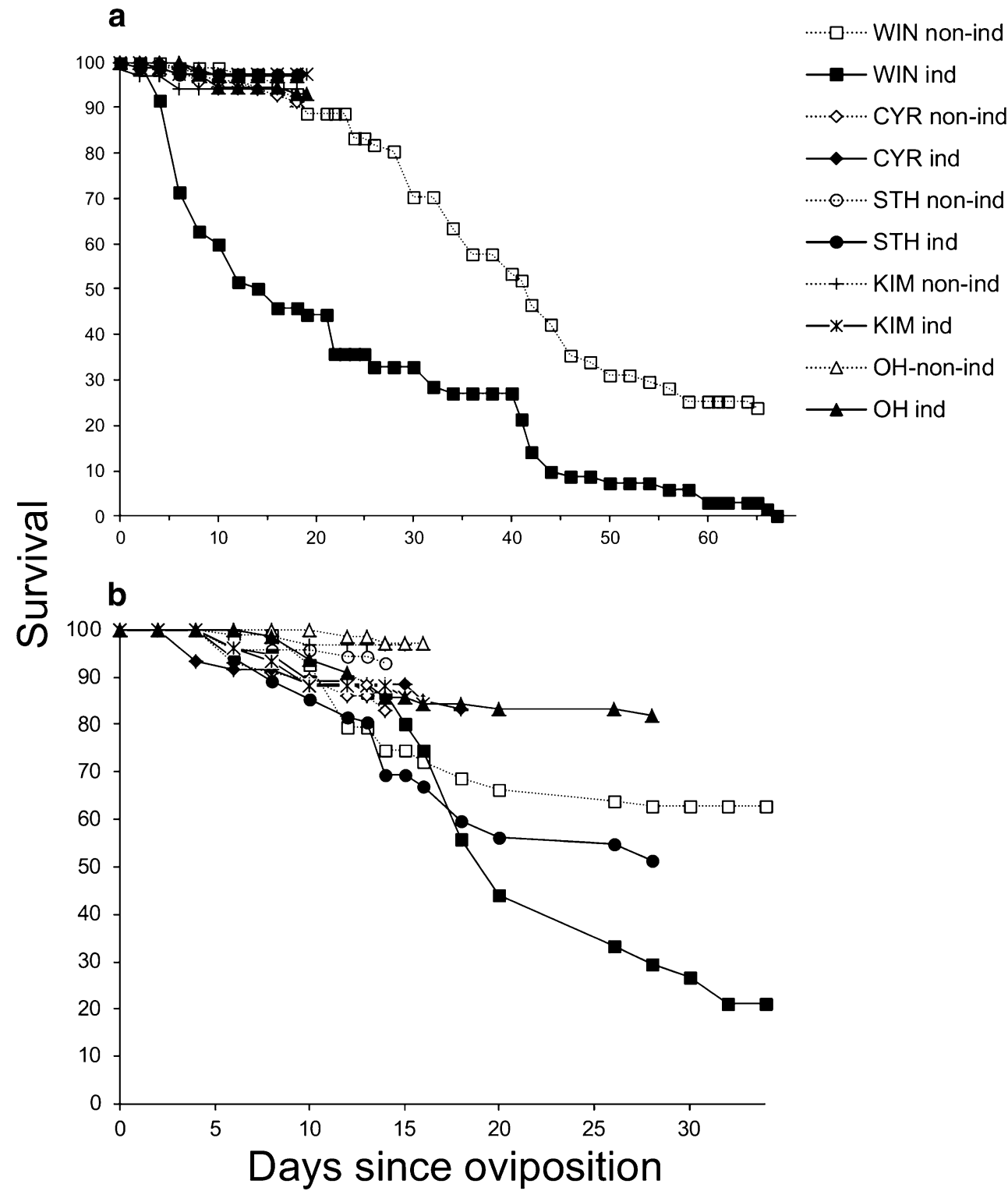

plants of this population contained small amounts of the aromatic GS 2-phenylethyl GS, whereas in the other two wild populations, all aliphatic GS classes were represented. Feeding by $P$. rapae increased levels of the indole GS and total GS concentration (indole GS, $F_{1,81}=59.0, P<0.001$; total GS, $\left.F_{1,81}=10.0, P=0.001\right)$. For the indole GS, the degree of induction depended also on the population (population-induction interaction $F_{4,81}=9.96, P<0.001$ ). The increase of indole GS was significant only for the wild populations (all $P$-values $<0.001$, Tukey-Kramer).

The final PLS analysis, from which the variables had been omitted that contributed little in explaining the variation, resulted in a model with two significant principal components explaining 46 and $25 \%\left(=\mathrm{R}^{2} \mathrm{X}\right)$, respectively, of the variance among the GS variables and 63 and $4 \%\left(=R^{2} Y\right)$, respectively, among the performance variables. The predictive value of this model was $65 \%\left(=Q^{2}\right)$. Each of the three performance parameters measured in healthy hosts, male wasps, and female wasps, respectively, were grouped together. Development time correlated negatively with both survival and biomass. Levels of 3-butenyl GS and 2-phenylethyl GS had a strong negative impact on insect performance, whereas levels of 3-methylsulfinylpropyl GS and 2-hydroxy-3butenyl GS positively correlated with insect performance. Indole GS had little effect on insect performance based on PLS analysis and only separated the wild populations from the cultivars.

\section{Discussion}

The results of this study show that the development of $M$. brassicae and Mi. mediator was similar on the two cultivars 


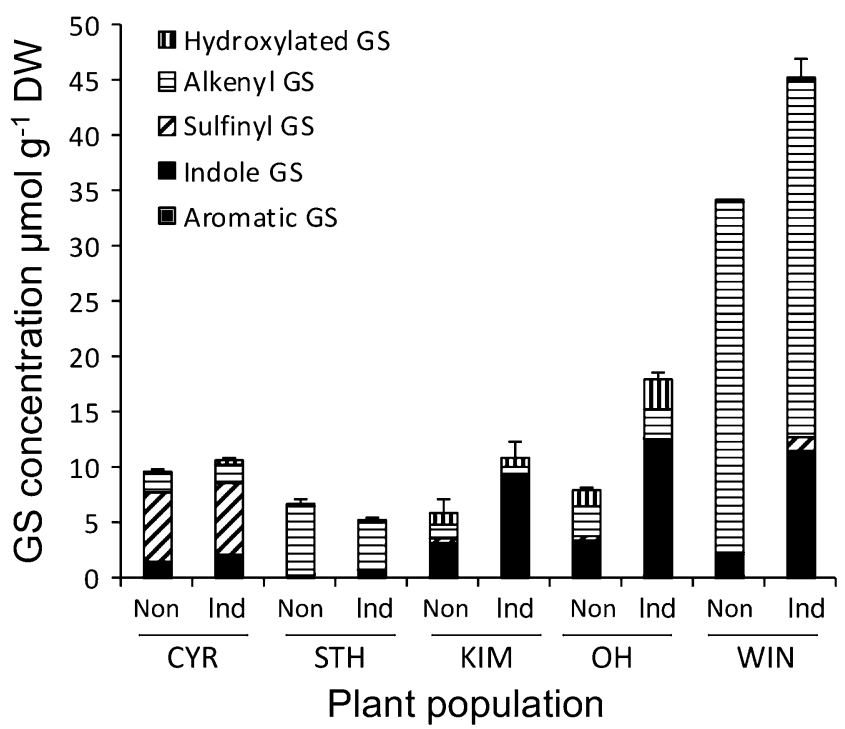

Fig. 3 Glucosinolate (GS) concentrations measured in samples taken from cultivated (CYR or STH) or wild cabbage (Brassica oleracea) plants originating from England (KIM, OH, WIN population). Samples were taken from non-induced plants (Non) and from plants that had been exposed to Pieris rapae feeding for $7 \mathrm{~d}$ (Ind). Concentrations of the detected 11 GS compounds were pooled for the three different GS classes: aromatic, indole, and aliphatic GS. Aliphatic GS were further subdivided into sulfinyl, alkenyl and hydroxylated GS. Bars give the mean values (+SE) for total GS concentrations. The number of samples varied between 8 and 10 per plant line and treatment

(CYR and STH) and the wild cabbage population KIM. Food plant quality of the wild populations ranked $\mathrm{KIM}>\mathrm{OH}>$ WIN based on visual inspection of the data. There also was a general decline in fitness correlates of the host and parasitoid when developing on plants that had been previously induced by $P$. rapae. However, survival to pupation of healthy $M$. brassicae caterpillars was high on all but the WIN population, irrespective of whether the plants had been induced or not. When the caterpillars developed on WIN plants, survival decreased dramatically. Moreover, on induced tissues of the WIN population, all caterpillars died. Surprisingly, aside from the WIN population, the effects of induction on survival were more pronounced on the parasitoid, M. mediator than on the herbivore, M. brassicae. In contrast, on WIN plants, parasitoid survival was higher than survival of unparasitized caterpillars on both non-induced and induced plants.

In many plant-herbivore associations, early instars are more susceptible to plant allelochemicals and other plant quality characteristics than later instars. In this case, mortality spikes during the first instar and then levels off as the larvae grow and become better able to detoxify and/ or excrete the plant's toxins (Zalucki et al., 2002). However, in our study, the effects of plant quality in WIN plants on the survival of M. brassicae and Mi. mediator were gradual on non-induced and induced plants. Micro- plitis mediator terminates its relationship with the host at an earlier stage of development (typically L3 or early L4), a point when the host is only approximately $5 \%$ of the mass of a fully grown healthy caterpillar (Fig. 4). We also noted that some caterpillars of $M$. brassicae feeding on WIN plants successfully molted to the 5 th instar, but were quite small $(<500 \mathrm{mg})$ and refused to eat after molting, generally perishing within a week or so. Furthermore, whereas the larval development of a healthy $M$. brassicae caterpillar can last up to 3 weeks or even longer, that of a parasitized caterpillar is less than half of this duration. This means that parasitized caterpillars are under fewer host-growth-related constraints than healthy caterpillars, and this may explain the discrepancy in survival of the host and parasitoid on induced and undamaged WIN leaf tissues, compared with the other strains/populations (Fig. 4). We have provided a conceptual graph (Fig. 4) showing that koinobiont parasitoids, such as Mi. mediator, which terminate their relationship with the host at a very early stage of development (e.g., when it is very small), may be less susceptible to plants of low quality than parastioids that either require the host to grow to a large final size or healthy hosts. This is because the effects of plant toxins may be cumulative over the course of herbivore/parasitoid development, or else because the insects are forced to interact with the plant for a longer period of time.

A previous study (Gols et al., 2008a) found that the performance of a specialist herbivore, Pieris rapae, and its solitary endoparasitoid Cotesia rubecula (a close relative of Mi. mediator) on the same wild populations of B. oleracea was less variable than found for the host and parasitoid used in this study. Moreover, whereas M. brassicae develops poorly on diets where concentrations of aliphatic and total GS are high, the specialist appears to be more sensitive to higher levels of indole GS (Gols et al., 2008a). This probably reflects adaptive differences in the two associations that relate to specialization via frequencydependent selection. Using Arabidopsis thaliana plants with mutations that greatly reduced levels of aliphatic GS, indole GS, or both, Müller et al. (2010) demonstrated that the growth of Trichoplusia ni, Manduca sexta, and Spodoptera exigua caterpillars, three lepidopteran species, were all negatively affected by the presence of aliphatic GS. Only the growth of $S$. exigua was negatively affected also by the presence of indole GS (Müller et al., 2010). The effects of plant quality on development and survival of both generalist and specialist herbivores often are proportional up the food chain (Gunasena et al., 1990; Ode, 2006; Gols et al., 2008a,b; Harvey et al., 2011), or else less welladapted parasitoids perform worse than their hosts as levels of direct plant defenses increase (Harvey et al., 2003, 2005; Ode, 2006; Gols et al., 2008b). By contrast, high concentrations of plant toxins sometimes impair the development 


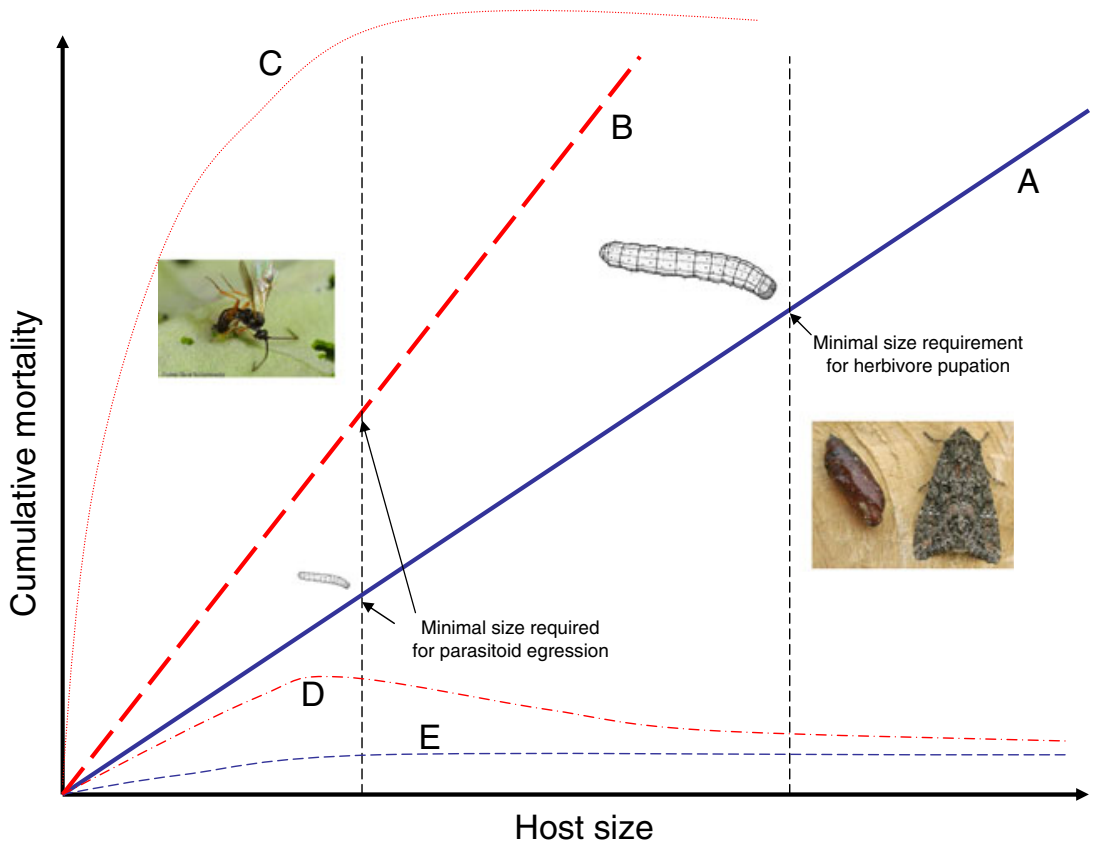

Fig. 4 Conceptual diagram showing the relationship between herbivore (healthy or parasitized) growth curves and cumulative mortality on food plants that differ in their quality. Solid line a and short dashed line e represent herbivore growth curves on non-induced plants; long dashed line $\mathbf{b}$, dotted line $\mathbf{c}$ and alternating dot-dashed line $\mathbf{d}$ lines represent herbivore growth curves on induced plants. In this example, the parasitoid is solitary and the host caterpillar must reach a much smaller critical size to support parasitoid development (left dashed black vertical line) than to successfully pupate (right vertical black dashed line). In this study, induction steepens the mortality curve (lines $\mathbf{a}, \mathbf{b}$ ) reducing survival of both the parasitoid and the herbivore; the latter does not survive at all on induced plants because it cannot grow large enough to reach a minimum viable size for pupation. If the plant is even more toxic, then the parasitized host does not even reach a critical size and all parasitoids die before egression form the host (line c). In some instances, perhaps due to stress caused by parasitism, parasitoids may experience higher mortality on induced plants than their hosts (line d), or else herbivore and parasitoid mortality on noninduced plants does not differ (line e). Many different combinations are possible, depending on the effects of the plant on the herbivore and parasitoid, the parasitoid on the herbivore, and quantitative differences in the required growth of healthy and parasitized hosts of the host more than that of the parasitoid (Devine et al., 2000; this study). In these examples, the outcome of the interaction may hinge on the effects that plant allelochemicals have on the physiology of the insects through processes associated with host-parasitoid nutritional ecology and/or on host immunity (Bukovinszky et al., 2009; Smilanich et al., 2009).

Analysis of allelochemicals in plant tissues revealed qualitative and quantitative variation among the populations. Furthermore, induction by $P$. rapae feeding mainly affected levels of indole GS, and these increased more in wild than in cultivated cabbage (see also Harvey et al., 2011). However, PLS analysis did not reveal a significant relationship between levels of indole GS and performance of the herbivore or the parasitoid. We only found a negative correlation between insect performance and levels of 3-butenyl GS and 2-phenylethyl GS. However, van Leur et al. (2008) demonstrated that the performance of $M$. brassicae was little affected when feeding on Barbarea vulgaris genotypes that produce 2phenylethyl GS at much higher concentrations than the WIN plants used in this study. The effect of plant induction on survival was more pronounced in the parasitoid than in healthy hosts. This suggests that something other than GS, with perhaps the exception of 3-butenyl GS, is responsible for the decline in insect performance, especially for the parasitoid. Primary metabolites, such as nitrogen, phosphorous, and carbon, were not measured in the current study, but previous research with crucifers suggests that nitrogen, often a limiting nutrient for insect development, is always present in high concentrations in Brassica species (Soler et al., 2005). It is more likely that some unidentified secondary plant metabolite(s), that is/are present in leaf tissues of cabbage plants is induced after herbivore damage. For example, highly toxic cardenolides have been found in addition to GS in leaf tissues of the crucifer, Erysimum cheiranthoides (Renwick, 2002). Cipollini and Gruner (2007) have isolated cyanide from leaves of the garlic mustard, Alliaria petiolata. The invasive crucifer, Bunias orientalis, is highly toxic to specialist herbivores although its main allelochemical, the aromatic GS sinalbin, is also present in other crucifers that are suitable food plants for these herbivores (Harvey et al., 2010b). 
In summary, this study has reported that differences in the quality of cultivated and wild cabbage plants affected the development and survival of a generalist herbivore and its solitary endoparasitoid. Differences in plant quality on insect performance were linearly correlated with concentrations of the aliphatic 3-butenyl GS, which in WIN plants exceeded some quantitative threshold for successful development. The poor quality of WIN plants also had a more serious affect on survival of the host, $M$. brassicae, than of its parasitoid, Mi. mediator, which probably reveals different temporal and physiological constraints imposed by the plant on both organisms. Thus far, more intimate aspects of life-history and development strategies in herbivores and their natural enemies in response to differences in plant quality have been largely ignored. Instead, researchers have tended to lump the insects according to their trophic status. By incorporating biological and physiological characteristics of the insects, such as their feeding strategies, growth patterns, and other relevant criteria, a better understanding of three (and higher) trophic level interactions will be attained.

Acknowledgments The authors thank Leon Westerd, Frans van Aggelen, and André Gidding for rearing Mamestra brassicae. Tibor Bukovinszky of 'Bugs in the Picture' (www.bugsinthepicture.com) for the photograph of Microplitis mediator, and CEntomart (www. entomart.be) for the photograph of M. brassicae. Ciska Raaijmakers is thanked for help in analyzing the glucosinolate profiles.

Open Access This article is distributed under the terms of the Creative Commons Attribution Noncommercial License which permits any noncommercial use, distribution, and reproduction in any medium, provided the original author(s) and source are credited.

\section{References}

Agrawal, A. A., and Kurashige, N. S. 2003. A role for isothiocyanates in plant resistance against the specialist herbivore Pieris rapae. J. Chem. Ecol. 29:1403-1415

ASKEW, R. R., and SHAW, M. R. 1986. Parasitoid communities: their size, structure and development, pp. 225-264, in J. Waage and D. Greathead (eds.), Insect Parasitoids. Academic Press, London, UK.

Barbosa, P., Saunders, J. A., Kemper, J., Trumbule, R., OlechNo, J., and MARTINAT, P. 1986. Plant allelochemicals and insect parasitoids effects of nicotine on Cotesia congregata (Say) (Hymenoptera: Braconidae) and Hyposoter annulipes (Cresson) (Hymenoptera: Ichneumonidae). J. Chem. Ecol. 12:1319-1328.

BENREY, B. and DENNOR, R. F. 1997. The slow growth-high mortality hypothesis: A test using the cabbage butterfly. Ecology 78:987999.

Bukovinszky, T., Poelman, E. H, Gols, R., Prekatsakis, G. Vet, L. E. M., Harvey, J. A., and Dicke, M. 2009. Consequences of constitutive and induced variation in plant nutritional quality for immune defence of a herbivore against parasitism. Oecologia 160:299-308.

Buskov, S., Serra, B., Rosa, E., Sorensen, H., and Sorensen, J. C. 2002. Effects of intact glucosinolates and products produced from glucosinolates in myrosinase-catalyzed hydrolysis on the potato cyst nematode (Globodera rostochiensis cv. Woll). J. Agr. Food Chem. 50:690-695.

CIPOLlini, D., and Gruner, B. 2007. Cyanide in the chemical arsenal of garlic mustard, Alliaria petiolata. J. Chem. Ecol. 33:85-94.

Devine, G. J., Wright, D. J., and Denholm, I. 2000. A parasitic wasp (Eretmocerus mundus Mercet) can exploit chemically induced delays in the development rates of its whitefly host (Bemisia tabaci Genn.). Biol. Cont. 19:64-75.

Eriksson, L., Johansson, E., Kettaneh-Wold, N., Trygg, J., WiKströM, C., and WolD, S. 2006. Multi- and Megavariate Data Analysis. Part 1: Basic Principles and Applications. Umeå, Sweden: Umetrics AB.

FAhEY, J. W., ZALCMANN, A. T., and TAlalay, P. 2001. The chemical diversity and distribution of glucosinolates and isothiocyanates among plants. Phytochemistry 56:5-51.

FordyCE, J. A., and SHAPIRO, A. M. 2003. Another perspective on the slow-growth/high-mortality hypothesis: chilling effects on swallowtail larvae. Ecology 84:263-268

FRITZ, R. S. 1982. Selection for host modification by insect parasitoids. Evolution 36:283-288.

Giamoustaris, A., and MithEN, R. 1995. The effects of modifying the glucosinolate content of leaves of oilseed rape (Brassica napus ssp oleifera) on its interaction with specialist and generalist pests. Ann. Appl.. Biol. 126:347-363.

Gols, R., and Harvey, J. A. 2009a. Plant-mediated effects in the Brassicaceae on the performance and behaviour of parasitoids. Phytochem. Rev. 8:187-206.

Gols, R., and HarveY, J.A 2009b. The effect of host developmental stage at parasitism on sex-related size differentiation in a larval endoparasitoid. Ecol. Entomol. 34:755-762.

Gols, R., WagenaAr, R., Bukovinszky, T., VAn Dam, N. M., Dicke, M., Bullock, J. M., and HarveY, J. A. 2008a. Genetic variation in defense chemistry in wild cabbages affects herbivores and their endoparasitoids. Ecology 89:1616-162.

Gols, R., Bukovinszky, T., Van Dam, N. M., Dicke, M., Bullock, J. M., and HarveY, J. A. 2008b. Performance of generalist and specialist herbivores and their endoparasitoids differs on cultivated and wild Brassica populations. J. Chem. Ecol. 34: 132-143.

Gunasena, G. H., Vinson, S. B., and Williams, H. J. 1990. Effects of nicotine on growth, development, and survival of the tobacco budworm (Lepidoptera: Noctuidae) and the parasitoid Campoletis sonorensis (Hymenoptera: Ichneumonidae). J. Econ. Entomol. 83:1777-1782.

Halkier, B. A., and GershenZON, J. 2006. Biology and biochemistry of glucosinolates. Annu. Rev. Plant. Biol. 57:303-333.

HARVEY, J. A. 2005. Factors affecting the evolution of development strategies in parasitoid wasps: the importance of functional constraints and incorporating complexity. Entomol. Exp. Appl. 117:1-13.

Harvey, J.A., HarveY, I.F., and ThOMPSON, D.J. 1994. Flexible larval growth allows use of a range of host sizes by a parasitoid wasp. Ecology 75:1420-1428.

Harvey, J.A., Jervis, M. A., Vet, L. E. M., Gols, G. J. Z., and JIANG, N. 1999. Development of the parasitoid, Cotesia rubecula (Hymenoptera: Braconidae) in Pieris rapae and P. brassicae (Lepidoptera: Pieridae): evidence for host regulation. J. Insect Physiol. 45:173-182.

HARVEY, J. A., VAN DAM, N. M., and Gols, R. 2003. Interactions over four trophic levels: foodplant quality affects development of a hyperparasitoid as mediated through a herbivore and its primary parasitoid. J. Anim. Ecol. 72:520-531.

Harvey, J. A., Bezemer, T. M., Elzinga, J. A., and Strand, M. R. 2004. Development of the solitary endoparasitoid Microplitis demolitor: Host quality does not increase with host age and size. Ecol. Entomol. 29:35-43. 
Harvey, J. A., Van Nouhuys, S, and Biere, A. 2005. Effects of quantitative variation in allelochemicals in Plantago lanceolata on development of a generalist and a specialist herbivore and their endoparasitoids. J. Chem. Ecol. 31:287-302.

Harvey, J. A., Poelman, E. H., and Gols, R. 2010a. Development and host utilization in Hyposoter ebeninus (Hymenoptera: Ichneumonidae), a solitary endoparasitoid of Pieris rapae and P. brassicae caterpillars (Lepidoptera: Pieridae). Biol. Cont. 53:312-318.

Harvey, J. A., Biere, A., Fortuna, T., Vet, L. E. M., Engelkes, T., Morrien, E., Gols, R., Verhoeven, K., Vogel, H., Macel, M., HeIDEl-Fischer, H. M., Schramm, K., and VAN Der Putten, W. H. 2010b. Ecological fits, mis-fits and lotteries involving insect herbivores on the invasive plant, Bunias orientalis. Biol. Inv. 12:3045-3059.

Harvey, J. A., VAN Dam, N. M., RaAijmakers, C. E., Bullock, J. M., and GoLS, R. 2011. Tri-trophic effects of inter- and intrapopulation variation in defence chemistry of wild cabbage (Brassica oleracea). Oecologia 166:421-431.

HOPKINS, R. J., VAN DAM, N. M., and VAN LOON, J. J. A. (2009) Role of glucosinolates in insect-plant relationships and multitrophic interactions. Annu. Rev. Entomol. 54:57-83.

JONES, R. L., and LEWIS, W. J. 1971. Physiology of the host-parasite relationship between Heliothis virescens and Microplitis croceipes. J. Insect Physiol. 17:921-927.

LAMPERT, E., and BowERS, M. D. 2010. Effects of plant diet on the quality of the generalist, Trichoplusia ni (Noctuidae), as a host for the polyembryonic parasitoid Copidosoma floridanum (Hymenoptera: Encyrtidae). Entomol. Exp. Appl. 134:287-295.

Li, Q., Eigenbrode, S. D., Stringham, G. R., and Thitagarajah, M. R. 2000. Feeding and growth of Plutella xylostella and Spodoptera eridania on Brassica juncea with varying glucosinolate concentrations and myrosinase activities. J. Chem. Ecol. 26:2401-2419.

Littell, R. C., Stroup, W. W., and Freund, R. J. 2002. SAS for Linear Models, 4th Edition. Cary NC, USA: SAS Institute Inc.

MorSE, D. H. 2009. Four-level interactions: herbivore use of ferns and subsequent parasitoid-hyperparasitoid performance. Ecol. Entomol. 34:246-253.

Moyes, C. L., Collin, H. A., Britton, G., and Raybould, A. E. 2000. Glucosinolates and differential herbivory in wild populations of Brassica oleracea. J. Chem. Ecol. 26:2625-2641.

Müller, R., De Vos, M., Sun, J. Y., SONDERBY, I. E., Halkier, B. A., WitTSTOCK, U., and JANDER, G. 2010. Differential effects of indole and aliphatic glucosinolates on lepidopteran herbivores. $J$. Chem. Ecol. 36:905-913.

Newton, E., Bullock, J. M., and Hodgson, D. 2009a. Bottom-up effects of glucosinolate variation on aphid colony dynamics in wild cabbage populations. Ecol. Entomol. 34:614-623.

Newton, E. L., Bullock, J. M., and Hodgson, D. J. 2009 b. Glucosinolate polymorphism in wild cabbage (Brassica oleracea) influences the structure of herbivore communities. Oecologia 160:63-76

ODE, P. J. 2006. Plant chemistry and natural enemy fitness: effects on herbivore and natural enemy interactions. Annu. Rev. Entomol. 51:163-185.

Ode, P. J., Berenbaum, M. R., ZANGerl, A. R., and Hardy, I. C. W. 2004. Host plant, host plant chemistry and the polyembryonic parasitoid Copidosoma sosares: indirect effects in a tritrophic interaction. Oikos 104:388-400.

RENWICK, J. A. A. 2002. The chemical world of crucivores: lures, treats and traps. Entomol. Exp. Appl. 104:35-42.

Smilanich, A. M., Dyer, L. A., Chambers, J. Q., and Bowers, D. M. 2009. Immunological cost of chemical defence and the evolution of herbivore diet breadth. Ecol. Lett. 7:612-621.

SMilowitZ, Z., and IwaNTSCH, G. F. 1975. Relationships between the parasitoid Hyposoter exiguae and the cabbage looper Trichoplusia $n i$ : the effect of host age on ovipositional rate of the parasitoid and successful parasitism. Can. Entomol. 107:689-694.

Soler, R., Bezemer, T. M., VAn Der Putten, W. H., Vet, L. E. M., and HARVEY, J. A. 2005. A multitrophic approach linking below and aboveground insects: the effects of root herbivory on the performance of an aboveground herbivore, its parasitoid and hyperparasitoid. J. Anim. Ecol. 74:1121-1130.

VAN DAM, N. M., Witjes, L., and Svatos, A. 2004. Interactions between aboveground and belowground induction of glucosinolates in two wild Brassica species. New Phytol. 161:801810.

Van Leur, H., Vet, L., Van Der Putten, W., and Van Dam, N. M. 2008. Barbarea vulgaris glucosinolate phenotypes differentially affect performance and preference of two different species of lepidopteran herbivores. J. Chem. Ecol. 34:121-131.

VINSON, S. B. 1972. Effect of the parasitoid, Campoletis sonorensis, on the growth of its host, Heliothis virescens. J. Insect Physiol. 18:1509-1514.

Zalucki, M. P., Clarke, A. R., and Malcolm, S. B. 2002. Ecology and behavior of first instar larval Lepidoptera. Annu. Rev. Entomol. 47:361-393. 